\title{
NOT-AT-ISSUE CONTENT IN THE REFLEXIVE-REFERENTIAL THEORY*
}

\author{
Eduarda Calado Barbosa** \\ https://orcid.org/0000-0002-2478-9670 \\ eduardacaladobarbosa@gmail.com
}

\begin{abstract}
The Reflexive-Referential Theory is a multi-content approach to utterance interpretation. Its main proponent, John Perry, assumes that utterances of sentences with singular terms express several contents, depending on how their utterers and interpreters harness information from the situations in which they are produced. However, the theory says little to nothing about implied content, like presuppositions. Here, I discuss the possibility of including presuppositions, defined in terms of the concept of not-at-issue content, in this view. I begin with a brief characterization of the Reflexive-Referential theory in what regards its theoretical motivations and main thesis, followed by a study case of presuppositional not-at-issue content associated to a specific class of singular terms, proper names. To conclude, I ponder over a few consequences of this overall project of theoretical expansion.
\end{abstract}

Keywords Content. Reference. Reflexivity. Presupposition. Not-at-issue content.

RESUMO A Teoria Reflexivo-Referencial pode ser definida como uma abordagem multiproposicional da interpretação de enunciações. Nesse sentido, seu proponente principal, John Perry, sustenta que enunciações de frases com termos singulares expressam vários conteúdos, a depender de como falantes/ intérpretes exploram a informação provida pelas situações nas quais elas são

* Article submitted on 12/09/2019. Accepted on 25/03/2020.

** Instituto de Investigaciones Filosóficas / Sociedad Argentina de Analisis Filosófico / CONICET. Buenos Aires, Argentina.

KRITERION, Belo Horizonte, nº 148, Abr./2021, p. 55-75 
produzidas. Entretanto, a teoria Reflexivo-Referencial diz muito pouco sobre conteúdos implicados, como pressuposições, por exemplo. Aqui, discuto a possibilidade de incluir pressuposições, definidas em termos do conceito de notat-issueness, no quadro da posição. Começo com uma breve caracterização de suas motivações e principais teses, seguida por um estudo de caso do conteúdo pressuposicional not-at-issue expresso por um tipo especifico de termo singular, os nomes próprios. Para concluir, pondero acerca de algumas consequências desse projeto geral de expansão teórica.

Palavras-chave Conteúdo. Referência. Reflexividade. Presuposição. Conteúdo not-at-issue.

\section{Introduction}

Perry (2001) tackles two objections to Referentialism: 1) the problem of coreference, concerning the cognitive significance of coreferential terms; and 2 ) the problem of no-reference, that is, accounting for the meaningfulness of singular terms that fail to refer ${ }^{1}$. With the purpose of addressing these objections, Perry advances a multi-content approach to singular reference, the Reflexive-Referential Theory (RRT), claiming, basically, that assertions with singular terms express several truth-conditional contents. One of them is the singular proposition expressed or the referential content of the utterance, of which the referent is a constituent. Another one is the reflexive content, which carries information purely from linguistic conventions and the production of the token; and, finally, incremented reflexive content, which contains partial information about the referent, but is still essentially about the utterance itself. In this view, an utterance of (1), for example,

(1) Barack Obama was the first African American president of The United States.

expresses not only the singular proposition (P1), but also the reflexive truthconditions in $\left(\mathrm{P}^{\mathrm{r}} 1\right)$ below, alongside incremented versions of $\mathrm{it}^{2}$.

1 Perry is an affiliate of the Referentialism advocated by the New Theories of Reference. These theories are characterized mainly by their criticism of descriptivist satisfactional semantics for proper names. I offer a more detailed characterization of the position in section 1.

2 I offer examples of incremented truth-conditions in section 3. 
(P1) that Barack Obama was the first African American president of The United States. (where the words in boldface represent the contribution of the referential term to the truth-conditions)

$\left(\mathrm{P}^{\mathrm{r}} 1\right)$ that the individual to whom the permitting naming convention associated to 'Barack Obama' in (1) refers was the first African American president of The United States. (in which the italics represent conditions of identification of the referent)

In Perry's view, reflexive content is pivotal to solve both objections to Referentialism. As we will see in the next section, it accounts for content individuation and cognitive significance - which arise from the objection in 1) -, without compromising central tenets of the position, such as direct reference. Also, according to the RRT, the information provided by a speech situation ${ }^{3}$ is loaded into reflexive rules ${ }^{4}$, the most basic level of semantic interpretation, in an incremental process up to higher levels of semantic specificity, the highest being the singular proposition expressed (Perry, 2000, pp. 194-199). This notion of incrementation will be particularly elucidating to solve the objection in 2), as well as to explain the meaningfulness of utterances in situations with scarce information about the referent.

According to a recent trend in pragmatic studies, originally proponed by Craige Roberts (1996), assertions express not only truth-conditional content, like referential or reflexive, but also implied content with a regulative function on conversations. Defenders of this new framework call it not-at-issue content. Content that, unlike those Perry (2001) focuses on, is implicit, backgrounded, and projectable.

Here, I will discuss the concept of content presented by the RRT relatively to instances of the no-reference problem. The idea is twofold. First, I intend to show that there is a relation between regulative not-issue content (presuppositions) and asserted content in informationally defective conversational interactions. Secondly, that shedding light on this relation can help explain kinds of asserted content. I do not mean to revise core notions of Perry's RRT, though. Rather, my most general point is to highlight issues that Perry left untouched in his initial

3 In Barwise and Perry's situational semantics (Barwise \& Perry (1983)), situations represent cognitively accessible limited parts of the real world. What I call a speech situation is simply a situation of information exchange in which language is used.

4 They are conditions of identification that tokens of sentences inherit from the type-expressions they contain. Reflexive rules have the form of linguistic rules, but they are about the token itself (Garcia-Carpintero, (2000)). 
project of an incremental semantics ${ }^{5}$. In particular, the role of conversations, the most common kind of human interaction for information exchange ${ }^{6}$, in utterance interpretation. I will begin by presenting a more detailed description of the concept of content itself in the next section. In section 2, I will deal with presuppositional content associated to proper names and define it in terms of the at-issue/not-at-issue distinction. Finally, in section 3, I end with a few observations about the impacts of the notion of not-at-issueness to the RRT framework.

\section{Motivating the RRT}

What has been called the Cognitive Constraint on Semantics (CCS) ${ }^{7}$ is the assumption that an adequate semantic theory must explain the cognitive significance of expressions (words and sentences), aside from offering an account of their conventional meanings and truth-valueness. Commitment to CCS, thus, imposes an extra demand on the semanticist, namely, that she provides an explanation of how interpreters cognize utterances: how utterances impact their mental organization and, ultimately, reflect into action.

As a theoretical concern, CCS relates to the more general philosophical question of how expressed content is to be individuated from a cognitively appropriate perspective for consistently coreferential terms, like 'Hesperus' and 'Phosphorus', for example; and also, for uses of different expression-types that only occasionally come to co-refer, like 'I', 'he' and 'Barack Obama' in (2), (3) and (1), respectively:

(2) I was the first African American president of The United States. (said by Barack Obama).

(3) That was the first African American president of The United States. (said by a speaker pointing at Barack Obama).

Referencialism would allegedly fail to account for the intuitive difference between the contents expressed by utterances of (1), (2) and (3) because its defenders tend to commit to four main tenets: a) Millianism about proper names; b) the claim that sentences with singular terms express singular propositions;

5 Perry is very unclear about how incrementation occurs and the various sources that can provide information for the process. My point is to expand his theory with a more specific treatment of the issue. With that purpose in mind, I looked for the best theory in the market concerning conversations and content, namely, Roberts' theory. The idea I will argue for here is to combine these two frameworks: the RRT and the AI/NAI distinction. In a broader sense, communication exchange usually happens in dialogical settings.

7 See Wettstein (1986) and Taylor (1995). 
c) the thesis that names are rigid designators; and d) that some singular terms - namely, indexicals, demonstratives and names - refer directly.

In what respects a), referentialists endorse one or another version of nonsatisfactional semantics ${ }^{8}$ for names, inspired by Millian intuitions. As it is well-known, Mill held that proper names function as tags relatively to their designata, that is, they do not connote their referents in any way. An important motivating intuition here is that one cannot reasonably ask for the meaning of a name. For instance, the answer to the question "what is the meaning of 'Barack Obama?" is not any form of connotation associated to Barack Obama, but the individual himself.

Tenet b), on its turn, ascertains that singular terms contribute to singular propositions with individuals. Notably, in Perry's Referentialism, singular propositions are structured, complex entities with constituent parts. So, a sentence such as (1) expresses a proposition that combines two parts: the property expressed by the predicate 'being the first African American president of the United States' and the semantic value of the word 'Barack Obama', namely, Barack Obama9.

Lastly, tenets c) and d) characterize the mechanism by means of which proper names refer. According to referentialists, the reference of a name is independent of the attributes that the name-bearer may instantiate. Reference is a conventional and direct mechanism of designation that depends on intentions of recovering causal chains of coreference. These ideas were developed firstly by Kripke (1980) and Kaplan (1989) and since then have been an important element of the Referentialist orthodoxy (Michaelson \& Reimer (2019)).

In dealing with the apparent complications raised by his subscription to Referentialism, then, Perry (2001) takes off with a distinction, borrowed and developed from Marti (1995), between three modes of designation: demonstrating, naming and describing. For the cases of (1), (2) and (3), according to his position, each sentence involves a different mode of designating Barack Obama, a different way of picking up the same referent. And this will determine different outcomes for semantic interpretation in what concerns the cognitive and epistemic aspects estimated by the CCS.

For example, compare (1) and (2). In hearing an utterance of (2), an interpreter that is ignorant of who she is talking to will come to know that her

8 In a non-satisfactional semantics, the contribution of a singular term is determined by a causal connection with the referent, as opposed to a descriptive condition that the referent happens to satisfy.

9 This approach on propositions faces a few problems concerning the relation between sentential components and propositional constituents. See Crimmins (1992) and Bealer (1982; 1993), Recanati (2002), Cappelen and Lepore (2007) and Sennet (2011). 
interlocutor was the first African American president of The United States, but not that he is named Barack Obama. If Barack Obama himself utters (1) to the same interpreter, without any indication that he is the referent of 'Barack Obama', the interpreter will not acquire the information that her interlocutor was the first African American president of The United States, though she will come to know that someone named Barack Obama was. Similarly, if asked about who the utterer of (2) was, she could rightly answer that he was the first African American president of The United States, something that she is not entitled to declare about the utterer of (1) in the above-mentioned case.

A more pragmatically oriented approach to the matter of cognitive significance and content individuation is offered by Perry in his more recent contribution with Kepa Korta (in Korta \& Perry (2011)). In discussing referential intentions, the authors present the concept of cognitive burden (or cognitive fix). Their idea is that, in information exchange, speakers make plans to refer to the objects they wish to talk about. Such plans are guided by what they call target intention: 'a vague intention of the type of cognitive fix on that object that $\mathrm{H}$ [the interlocutor] should have, in order to be in a position to have whatever further thoughts and actions $\mathrm{S}$ [the speaker] has in mind for him; that is, an apt cognitive fix' (Korta \& Perry, 2011, p. 43). Modes of designation will play an important role in the accomplishment of plans of referring, in the sense that the mechanisms they involve - denotation via descriptive conditions, for descriptions, and reference via convention, for names, for example - reflect how the interpreter is required to cognize the designatum. But I will return to this topic in sections 3 and 4.

For now, it is important to have in mind only that Perry's semantic theory, in accordance with CCS, predicts that the reflexive counterparts of singular terms will make a difference for the rational reconstruction of cognitive states. One among Perry's motivation for establishing a theoretical commitment to CCS has to do with his idea that semantics and agency are irrevocably related. Semantic content explains how agents navigate the world and understand each other's minds and reasons for acting; and the cognitive significance of language emerges as a relevant matter because it sheds light on the conditions under which information regarding meaning and reference impact mental states, on the one hand, and rationality, on the other. The analysis of examples (1), (2) and (3), purports to show precisely that, in the RRT, reflexive content is what accounts for the felt difference between the contents expressed by the utterances, given that reflexivity is the semantic level that properly explains away potential adjustments in the interpreters' mental organizations. That is one of the reasons why the reflexive/referential distinction is necessary. 
The other is to explain the meaningfulness of utterances in which reference is unsuccessful, as (1), when the interpreter is ignorant of who Barack Obama is. In this case, she will have information mainly from linguistic encoding, competence and behavior to make sense of what has been said by the utterer. Reflexive truth-conditions will then help explain another strong intuition: that such utterances still convey something, even when reference cannot be established in the face of informational discrepancies that hinder incrementation.

Hence, in the RRT, reflexive content has as one of its theoretical functions to explain how interpreters approach their interlocutors' belief states and actions under rational assumptions, even when information is scarce ${ }^{10}$. In generalizing this last claim, we have that any sentence $n$ with a singular term expresses a system of contents composed by $(\mathrm{Pn}),\left(\mathrm{P}^{\mathrm{r}} \mathrm{n}\right)$ and potentially various $\left(\mathrm{P}^{\mathrm{i}} \mathrm{n}\right)$, as illustrated by table 1 .

Table 1. Kinds of expressed content and when they are used

\begin{tabular}{|l|l|}
\hline Kinds of content & $\begin{array}{l}\text { When they are used to interpret utterances } \\
\text { with singular terms }\end{array}$ \\
\hline $\begin{array}{l}\text { Reflexive truth-conditional } \\
\text { content } \\
\left(\mathbf{P}^{r} \mathbf{n}\right)\end{array}$ & $\begin{array}{l}\text { When the interpreter is unable to determine } \\
\text { reference. }\end{array}$ \\
\hline $\begin{array}{l}\text { Referential content } \\
\text { (Pn) }\end{array}$ & When the referent is identified \\
\hline $\begin{array}{l}\text { Incremented truth-conditions } \\
\left(\mathbf{P}^{i} \mathbf{n}\right)\end{array}$ & $\begin{array}{l}\text { When facts other than just the linguistic } \\
\text { conventions are available, but the referent is } \\
\text { not determined. }\end{array}$ \\
\hline
\end{tabular}

I mentioned earlier, however, that the RRT does not include implied content, like presuppositions, in its architecture. In the remaining of this work, I intend to contribute to the development of the framework by discussing what place this form of implied content would occupy in a multi-content system of utterance interpretation.

10 The concept of classification may be important here. According to Perry, we, humans, are information-content harnessing beings. So, in navigating the world and interacting with each other, we are constantly extracting, storing and sharing information from (and within) situations. The way this is achieved is by classificatory practices of discrimination and categorization that order experience and enable folk psychological states, such as beliefs (O’Rourke \& Washington (2007)). 


\section{Presuppositions and not-at-issue content}

Contemporary linguists adopt at least two different strategies in dealing with presuppositions. One, which I will call the Projection Strategy, is to enlist lexical items and syntactic constructions that carry associated implicit propositions as presupposition triggers, and then test them for projection patterns in embedment. Typically, this is done with Family of sentences tests, exemplified below with sentences from (4) to (6).

(4) Was Barack Obama the first African American president of The United States? (interrogative)

(5) If Barack Obama was the first African American president of The United States, then he was important for his country. (conditional)

(6) Barack Obama was not the first African American president of The United States. (negation)

(E) Barack Obama exists.

The example purports to test if the existential presupposition (E), presumably triggered by the proper name 'Barack Obama', is projectable. Identifying the projective character of an exemplar of implied content is considered a good way of determining if it is presupposed rather than implicated (cf. Simons et al (2010)). The idea is that if (4)-(6) presuppose (E), like (1) does, we have evidence that $(\mathrm{E})$ is conventionally triggered by 'Barack Obama'. Thereupon, we have grounds to add proper names to the list of presupposition triggers.

Nonetheless, important objections have been raised to the predictions of global projection suggested by Family of sentences tests since the 1970s at least. For example, by Kempson (1975) and Soames (1989), who show that some disjunctions and conditionals cancel the existential presuppositions associated to definite descriptions and proper names. Take (7) and (8),

(7) Either the queen of Tonga rules despotically or there is no Queen of Tonga.

(8) If Ellery Queen has crossed America on a monocycle, Ellery Queen must exist. ${ }^{11}$

In these instances, the existential presuppositions that are associated to the singular terms are incompatible with what is asserted by the corresponding subordinate clauses, generating a cancellation effect. Much of the discussion on projection, as a matter of fact, has focused on attempts to unveil the contextual and/or phrasal elements that block or remove presuppositions. Some, by offering compositional treatments, like Karttunen (1971 a; 1971b; 1973; 1974). Others, by trying to put forward more flexible criteria that still allow for prediction but 
cannot be grasped by algorithms. Nevertheless, projection continues to be used as a form of identifying presuppositions.

The other strategy commonly used to explain presuppositions is to look at accommodation in discourse. This path has been adopted primarily by Common Ground accounts of assertion (Stalnaker, 1973; 1974; 2002; 2014) and theories of Discourse Information Structure, such as in Van der Sandt (1992) and Beaver (1992). These theorists test pragmatic reactions to the appropriateness of new assertions and the repairing mechanisms that maintain collaboration. In this line of analysis, they investigate how presuppositions affect the information flow of a conversational common ground, and their normative role relatively to new contributions.

The notion was first developed in philosophical literature by Lewis (1979), who defines conversational interactions with an analogy to scores of baseball matches. He claims that each move or contribution in a conversation has an abstract normative dimension. Talking to other people is not simply a matter of information exchange but it requires applying rules, placing the participant in an evaluative function. Accommodation is one of such rules. It determines that if a presupposition is necessary for the success of a conversational move, participants, as scorekeepers, will charitably add it to the set of propositions of the context, basically to avoid an infringement or the ultimate collapse of the conversation.

Though projection and accommodation still appear as defining features of presuppositions, new works have started to treat presupposed content in contrast with the notion of at-issueness. Roberts et al (2009), for example, agree that expression-types have components which exhibit projective behavior. However, they sustain that, contrary to what is assumed by Projection Strategies, projection is not by itself fine-grained enough to count as a criterion of demarcation for presuppositions. They offer convincing empirical data showing that other forms of implicit content also project, like Horn's assertorically inert entailments ${ }^{12}$, and conventional as well as some conversational implicatures. This conclusion led them to propose that projective behavior is the ultimate distinctive property not only of presuppositions, but of implied content in general, what they call not-at-issue (NAI) content.

The distinction between at-issueness and not-at-issueness developed by Roberts et al (2009) takes up from Roberts (1996). A summarized version of the position appears in the following fragment. transparent to NPI-licensing. For discussion, see Xiang, Grove, and Giannakidou (2015). 
The model is a simple one, taking information exchange to be the principal goal of discourse. There are two basic types of discourse move: questions (which establish immediate discourse goals) and assertions (which move the discourse towards accomplishment of these goals). All speech acts, or discourse moves, including assertions, are subject to a constraint understood as a consequence of Gricean Relevance: they must in some way address whatever question has most recently been accepted as the immediate goal of the discourse. This question Roberts calls the current Question Under Discussion, or QUD. Within this framework, we construct a distinction between what we will call at-issue and not-at-issue content of an utterance. At-issue content is content which is intended by the speaker to accomplish a conversational move i.e. to address the QUD or to raise another QUD which is relevant to the present one. (Roberts et al., 2009, p. 4)

The distinction between AI (at-issue) and NAI content is thus built on the assumption that, in conversational settings, speakers are scorekeepers that evaluate moves relatively to how they contribute to the accomplishment of common goals (stipulated by the set of participants). Such common goals, on their own turn, can be identified in terms of questions under discussion (QUDs): questions that the conversational interaction aims at responding. Expressed content that does not directly address the most recent QUD of a given conversation will exhibit the semantic profile that characterizes NAI content, i.e., it will be projectable and backgrounded. Moreover, it will be evidenced by the following tests:

i. Direct denial/confirmation tasks: because QUDs constraint possible conversational moves, at-issueness and not-at-issueness are most commonly tested with speakers being asked yes or no questions about the QUD.

ii. Tests of indirect denial of the Hey! Wait a minute! Type: These tests are lengthily discussed by von Fintel (2004), who proposes to diagnose the presence of existential presuppositions exploring pragmatic reactions to spurious uses of definite descriptions. According to him, the proper reply to an utterance of the classic example of 'The present King of France is bald' is a request for context revision, such as, 'Hey! Wait a minute! I didn't know that France was a monarchy'. Supposedly, the possibility of Hey! Wait a minute replies evidence that there is a discrepancy between what is being presupposed by the conversational participants in what respects the referent's existence.

iii. Intuitions of truth-value gap: presuppositional not-at-issue content affects contexts of evaluation, generating intuitions of truth-value gap. An occurrence of the sentence 'The king of France is bald' nowadays is again a good example: it is a meaningful assertion that cannot be evaluated at present times as either true or false ${ }^{13}$.

13 The tests in ii. and iii. are inspired by Strawson's account of referential failure for definite descriptions (Strawson (1950)). He holds that only agents using definite descriptions refer, not the definite descriptions themselves. In his theory, different uses determine different aboutness. Speakers may nevertheless use definite descriptions spuriously, for instance, when talking about nonexistent individuals, like the king of France. The outcome in such cases is a "feeling of squeamishness", spurred by the violation of the presupposition that the referent of 
iv. Finally, appropriateness of new moves in-the-context, according to principles of rational cooperation (Roberts (2015)).

Tests to identify presuppositional not-at-issue content would therefore encompass not only projection, but also intuitions of context-revision and truthvalue gap, along with responses the QUDs. In the next part of this section, I will discuss two types of not-at-issue content that I take to be associated to uses of proper names and show tests that ground this diagnosis.

\subsection{What we presuppose when we use names}

In this sub-section, I will discuss a few examples of conversations in which proper names are used, exploring intuitions of presence/absence of presupposition, according to suggestions from Roberts et al (2009). Subsequently, I will present a compact analysis of what I take the obtained results to indicate about uses of proper names.

Let us start with C1, a conversation between Jack and Jim, two teenagers whose school assignment is to form a list of famous Russians together.

\section{C1}

Jack: (9) Anna Karenina is Russian.

Jim: But Anna Karenina doesn't exist, she is from a book.

Jack: The teacher didn't say that we had to name only real people. Anna Karenina is famous and Russian!

As we can see, in $\mathrm{C} 1$, Jack has a plan of referring to Anna Karenina by means of the use of the name 'Anna Karenina'. Now, Jim's response to (9) is an attempt to make explicit something that is presupposed by Jack's utterance ${ }^{14}$, namely, a presupposition to the effect that Anna Karenina exists. This piece of information is backgrounded in the sense predicted by Roberts's NAI tests, as 1 and 2 below show.

the definite description exists. Strawson then explains referential failure in terms of presupposition failure and intuitions of truth-value gap.

14 As suggested by Simons (2001; 2005), presuppositions might have different sources. In the case of C1, the existential presupposition is also related to the assignment itself, namely, the task of naming individuals. The idea of the example is to show that Jim and Jack have different understandings of what is presupposed in the task, but also that they are authorized to discuss the presuppositions that are sanctioned by the uses they make of the proper name 'Anna Karenina'. 
1. Hey! Wait a minute test: Implies, by means of an indirect denial, that Anna Karenina is not real and thus (9) does not count as an appropriate move in $\mathrm{C} 1$.

Indirect denial in C1:

'[Hey! Wait a minute!] Anna Karenina is not real; she is from a book'.

2. Current $Q U D$ in C1: Is Anna Karenina a famous Russian?

Direct denial: replying 'Yes' or 'No' commits one to $e$.

$e$ : Anna Karenina exists.

Moreover, by uttering (9) in C1, Jack indicates that he takes for granted that Jim knows to whom 'Anna Karenina' refers. This assumption that the interlocutor is familiar with the referent ${ }^{15}$, which I will identify as a presupposition, seems to function as a kind of requirement for the completion of the agent's plan of referring. To better understand this claim, take $\mathrm{C} 2$, a conversation about the same school assignment.

\section{$\mathrm{C} 2$}

Jack: (9) Anna Karenina is Russian.

Jim: (10) Who is that?

Jack: She is the main character of a famous Russian book.

Now, tests 3 and 4 below show that the presupposition of familiarity with the referent is also backgrounded in the sense predicted by Roberts.

3. QUD in C2: Is Anna Karenina a famous Russian?

Direct denial: replying 'Yes' or 'No' commits one to $f$.

$f$ : one knows to whom 'Anna Karenina' refers.

4. Hey! Wait a minute test: Implies that the interlocutor does not know to whom 'Anna Karenina' refers.

Indirect denial in $C 2$ :

'[Hey! Wait a minute!] Who is that?'.

15 What I call the presupposition of familiarity with the referent of a proper name (the presupposition of familiarity, for short) is inspired by the notion of weak familiarity put forward by Roberts (2003). One of the cases in which a referent can be said to be weakly familiar is if 'the entity referred to is globally familiar in the general culture or at least among the participants in the discourse, although not mentioned in the immediate discourse' (Roberts, 2003, p. 304). In this sense, in C1, Jim acts as someone who takes the referent of 'Anna Karenina' as familiar to his interlocutor. 
Tests 1-4 show that the two presuppositions, existence and familiarity with the referent, are NAI contents, whose projective behavior can be evidenced by intuitions regarding questions under discussion and reactions to controversiality (the Hey! Wait a minute! replies).

My suggestion is that, from a semantic standpoint, this imposed cognitive burden can be partially explained by some properties of the type-expression, and, from a pragmatic ${ }^{16}$ standpoint, it can be explained by the pragmatic principles of retrievability and non-controversiality, which I will define in what follows.

First, consider the semantic standpoint. The mechanism through which names pick their designata, at least according to Referentialism, is essentially direct. Causal theories of reference state that objects are named according to permitting naming conventions that link the name to the name-bearer, allowing speakers to refer to the same thing cross-contextually, in a syntactic-lexically ordered way that is independent of non-linguistic contingent attributes that the referent may instantiate (Taylor (2015)) ${ }^{17}$.

The distinctive features of naming are best seen if we compare it to another conventional mode of designation, like demonstrating. It is well accepted that, in the successful cases of demonstration, a salient individual becomes a demonstratum when it satisfies certain conditions that have to do with perception and are built in the demonstrative's conventional meaning. Naming will differ from demonstrating, among other reasons, because it is not context-dependent in the same sense. So, it seems that the choice of a conventional mode of designation in a plan of referring will depend, in part, on how the type-expression relates to the context of utterance. In using a proper name, for instance, the speaker will typically assume (or presuppose) that her interlocutor has a previous route of access to the referent that is not perceptually anchored in the context.

Consider now the pragmatic standpoint, which I take to be more relevant to our explanatory purposes. Typically, the accomplishment of a plan of referring follows what is established by the pragmatic principle of retrievability, viz.: 'in order for an utterance to be a rational, cooperative act in a discourse interaction $\mathrm{D}$, it must be reasonable for the speaker to expect that the addressee can grasp the speaker's intended meaning in so-uttering in D' (Roberts, 2012, p. 75). In respecting retrievability thus the speaker commits to taking her

16 I use the contrast between the semantic and the pragmatic here to mark a distinction between what is conventional and what is conversational.

17 Taylor (2015) claims that semanticists have mistakenly focused too much energy on explaining reference in terms of word-world relations, thus neglecting word-word relations, where the key to solving many classical problems, such as coreference, really is. Furthermore, Taylor argues that names work as anaphoric devices. 
interlocutor's informational status into consideration, that is, to acknowledge what her interlocutor already knows before her assertion. This step will prevent conversational contributions that are either too informative or not informative enough. In the case of a proper name, as in the utterance of (9) in C2, Jack, for example, is blatantly violating his addressee's expectation of grasping his intended meaning.

The principle of non-controversiality (Grice (1981) and Abbott (2000; 2008)) is important here too ${ }^{18}$. According to it, an information can only be presupposed if it is not controversial; otherwise, it must be asserted. Jim's utterance of (10) in $\mathrm{C} 2$ can be seen as a request of context revision caused by the violation of both retrievability and non-controversiality, since the information of who the referent is is not uncontroversial to the interlocutor, requiring, thence, explicit articulation.

Now, in what regards the presupposition of existence, proper names are considered presupposition triggers in the classical sense ${ }^{19}$. As showed before, they pass a simple family of sentences test. That might initially suggest that the existential presupposition is semantic (conventional), but we also have evidence that non-semantic factors can block it. Consider metafictional discourse, for example. In C3 below, Jack and Jim are asked to make a list of Russian literary characters.

\section{C3}

Jack: (9) Anna Karenina is Russian.

Jim: But Anna Karenina doesn't exist, she is from a book.

Jack: That's exactly why she should be on the list. Didn't you understand the assignment?

Jim's comments on Jack's utterance of (9), in C3, is inadequate because he asserts something that was already presupposed, violating non-controversiality. The intuitions about the dialogue indicate that the linguistic behavior of the presupposition of existence is sensitive to pragmatic aspects. After all, the proper name is being used to talk about fiction, a non-veridical linguistic interaction ${ }^{20}$ that authorizes the expectation that the token of 'Anna Karenina' does not refer to an existing individual. In the last part of this work, I will

18 Though I take the principles of non-controversiality and retrievability as key Gricean notions, conversational maxims, such as relevance, are part of Roberts' framework too (see Roberts (2012)). They influence the determination of the QUD.

19 Familiarity with the referent does not seem to exhibit the same projective behavior as the presupposition of existence in Family of sentences test, specifically in the scope of conditionals and interrogatives.

20 See Walton (1990) and Friend (2006) for more about metafictional discourse and make-believe practices. 
discuss the idea of combining Perry's framework and the at-issue/not-at-issue distinction in dealing with proper names.

\section{NAI content in the Perryan system of contents}

Perry's theory is about how the linguistic and the information contents conveyed in speech situations adjust to one another to allow for the interpretation of utterances. As I pointed out in section 1., the architecture of contents he proposes is meant to explain the co-reference and no-reference problems, according to a principle of cognitive adequacy (the CCS). In what concerns the no-reference problem particularly, his theory serves the purpose of explaining those situations in which the content expressed by an utterance is not equivalent to the content the speaker intended to express. I presented this idea with examples like the utterance of (1) - Barack Obama was the first African American president of The United States - when the interpreter is ignorant of who Barack Obama is. In cases such as these, the interpreter acquires a belief whose content is reflexive, as predicted by the CCS, and not referential (the intended final content in paradigmatic cases).

Nevertheless, the system of contents predicted by the RRT does not seem to be exhausted by the reflexive-referential classification if we take conversations into consideration. Firstly, the reason to include conversations is commonsensical: they are the most common site of human communication and information exchange. In discussing the pragmatics of reference in his book with Kepa Korta, Perry himself acknowledges that fact, even though he and Korta approach the role of conversations in interpretation from an agential perspective (in explaining acts of referring) (Korta \& Perry, 2010, pp. 12-15; pp. 24-28).

The observations I am putting forward here arise in the context of implementing the incremental semantics of the RRT not from an agential standpoint solely, but mainly from a discursive one. As I tried to show in section 2., conversations include what speakers presuppose - partly in virtue of the lexical items that they choose to use - and how these presuppositions regulate new contributions and the contents they express. In this last section, I will argue that informationally defective conversations in which the no-reference problem is manifested can also be explained in terms of discourse information structure in conjunction with the concept of QUD and the AI/NAI distinction.

With that in mind, consider table 1 again. It purportedly shows that there are three kinds of content expressed by assertions: reflexive, incremented and referential. Now, we will add the conversational interactions $\mathrm{C} 1, \mathrm{C} 2$ and $\mathrm{C} 3$ in order to establish the asserted and implied contents expressed in each case. 
Remember that in C1, Jim, though familiar with who the referent of 'Anna Karenina' is, replies to Jack that Anna Karenina is a fictional character. In C1 then familiarity is a satisfied condition. As for existence, it is triggered in both $\mathrm{C} 1$ and $\mathrm{C} 2$, but its status as a common ground presupposition is different in each conversation: while, in $\mathrm{C} 1$, Jim states its falsehood, in $\mathrm{C} 2$, its truth-value is not brought up as relevant. Finally, in C3, familiarity is a satisfied condition and existence is blocked ${ }^{21}$. These considerations are shown in table $2^{22}$ :

Table 2. Asserted and implied contents in conversational settings

\begin{tabular}{|c|c|c|c|c|}
\hline Content & $\begin{array}{l}\text { Not-at-issue } \\
\text { content }\end{array}$ & & $\begin{array}{l}\text { Contribution of } \\
\text { the Proper Name }\end{array}$ & $\begin{array}{l}\text { Conversational } \\
\text { interaction }\end{array}$ \\
\hline & $\begin{array}{l}\text { Familiarity } \\
\text { with the } \\
\text { referent }\end{array}$ & $\begin{array}{l}\text { Existence of } \\
\text { the referent }\end{array}$ & & \\
\hline $\begin{array}{l}\text { Reflexive } \\
\text { content } \\
\left(P^{r} n\right)\end{array}$ & Not satisfied & Triggered & $\begin{array}{l}\text { The individual } \\
\text { to whom the } \\
\text { permitting naming } \\
\text { convention } \\
\text { associated to the } \\
\text { token of the proper } \\
\text { name } x \text { in (n) } \\
\text { refers. }\end{array}$ & $\mathrm{C} 2$ \\
\hline $\begin{array}{l}\text { Incremented } \\
\text { truth- } \\
\text { conditions } \\
\left(P^{i} n\right)\end{array}$ & Satisfied & $\begin{array}{l}\text { Either false } \\
\text { or blocked }\end{array}$ & $\begin{array}{l}\text { The individual } \\
\text { to whom the } \\
\text { permitting fictional } \\
\text { naming convention } \\
\text { associated to the } \\
\text { token of the proper } \\
\text { name } x \text { in (n) } \\
\text { purports to refers. }\end{array}$ & $\mathrm{C} 1 ; \mathrm{C} 3$ \\
\hline $\begin{array}{l}\text { Referential } \\
\text { content }^{23} \\
(\mathbf{P n})\end{array}$ & Satisfied & True & The individual & $\begin{array}{l}\text { Cases of } \\
\text { referential } \\
\text { success }\end{array}$ \\
\hline
\end{tabular}

21 This example involves fiction, but increments may have various sources. For example, the contribution of a demonstrative in cases in which a distracted speaker points at an empty spot will be an indexed location.

22 In what concerns the formulation of the contribution of the fictional name to the (Pin) in table 2 , I use the notion of 'purport to refer', which I borrow from Taylor (2015), to differentiate purport to refer from referential success.

23 Take the example of (1). Referential content (P1) will be the content expressed if the reference of 'Barack Obama' can be determined. 
The new table suggests that when the reference of a proper name cannot be determined for reasons having with hoe information is harnessed and, in addition, one of the two presuppositions is either blocked or not satisfied ${ }^{24}$, the content expressed will not be referential. When familiarity is not satisfied, the content expressed will typically be reflexive, as in $\mathrm{C} 2$. When existence is either false or blocked, but familiarity is satisfied, the content expressed will be incremented, as in $\mathrm{C} 1$ and $\mathrm{C} 3^{25}$.

Still, table 2 needs to be taken cautiously. Firstly, because it is incomplete. On the one hand, it explores only a subset of possible combinations between at-issue (truth-conditional) and not-at-issue contents. On the other, there might be other not-at-issue regulative assumptions linked to proper names, such as uniqueness and rigidity ${ }^{26}$, with different degrees of conventionality, that I am simply not considering here. Secondly, because I am not assuming that there is a relevant causal relation between kinds of truth-conditional content and the regulative assumptions I identified as presuppositional not-at-issue content. Rather, I am suggesting that the QUD and the NAI contents expressed by an utterance in a conversation can be used to explain what content was asserted by the utterer.

Take one last example. Suppose that you are part of the conversation about fictional characters from Russian literature, C4, and you hear (9). Let us assume that you are not familiar with the name 'Anna Karenina'. In this case, you know that only assertions about fictional characters from Russian literature count as acceptable moves, that is, as moves that answer the QUD. This authorizes you to infer that Anna Karenina, whoever she is, does not exist ${ }^{27}$. The utterance will, thus, inform you (Pig) ${ }^{28}$.

(Pi9) that the individual associated to the fictional permitting naming convention 'Anna Karenina' used in (9) is Russian.

24 In C1, the presupposition is false. This fact is made explicit by Jim's reply to (9). In C3, a conversation involving metafictional discourse, the presupposition was supposed to be blocked. So, one of the reasons why Jim's reply to (9) in C3 is inadequate is because it is about a presupposition that was supposed to be blocked.

25 It is important to remark, however, that while all three conversations, C1, C2 and C3, exemplify problems with information harnessing and cooperation, 'Anna Karenina' is a fictional name and, therefore, ultimately fails to refer successfully - for lexical-semantic reasons (that are independent from discourse information structure). The explication of C1-C3 that I presented here focuses not on referential failure, but on presupposition failure (when the presupposition is false or blocked): when participants make different assumptions regarding the QUD - as in C3 - or fail to identify what NAI contents are mutually manifest at a certain point - as in C1 and C2. I take both referential failure and presupposition failure to be instances of the no-reference problem.

26 For example, informational uniqueness (Roberts (2003)). For presuppositions related to rigidity, see Maier (2009).

27 Notice that it is the QUD, constrained by conversational principles of rational cooperation, that ultimately determines what content will be expressed.

28 In this scenario, which is not included in table 2, the truth-conditional content expressed is incremented, but the presupposition of familiarity is not a satisfied condition. 
There is a clear sense in which the common communicative goals of the conversation restrict how you cognize the utterance of (9). To be more precise, you will assume that the permitting naming convention by means of which 'Anna Karenina' purports to refer is fictional. Knowing which presuppositions are blocked will, in cases such as this (of metafictional discourse), impact your belief states as an interpreter. The interesting consequence here is thus to show how the QUD will determine which NAI contents are informative for the rational reconstruction of the agent's cognitive state. Consequently, similarly to the original version of the RRT, the implemented version I am arguing for here, satisfies the demands of the CCS. The semantic contents it predicts are cognitively adequate relatively to conversational interactions.

If we take one last look at table 2 and the example of $\mathrm{C} 4$, then, we will arrive at the more general conclusion that it is the QUD that ultimately determines how the NAI contents affect classificatory practices and semantic content. This would be a definitive motivation to include a description of how conversations, understood in terms of QUDs and NAI content in a multi-content approach, affect the determination of singular reference.

\section{Conclusion}

I tried to show here that, because RRT seeks to defend Referentialism from important objections as well as to preserve a cognitive constraint on semantics, it leaves out some nuances in what concerns kinds of content. I focused especially on the distinction between the at-issue and not-at-issue (AI/NAI) contents conveyed by assertions of well-formed sentences with proper names. As I hope to have shown in applying the tests involving QUDs in section 2., uses of proper names convey NAI contents, such as an existential presupposition and the presupposition that the interlocutor has familiarity with to whom the proper name purports to refer. I held that these presuppositional NAI contents can be recruited to account for the expressivity of utterances in informationally defective situations. In section 3, I claimed that the RRT was forged to deal with utterance situations and not with the normative features of interpretation within conversations. The benefit that can be drawn from my suggestion of implementing the RRT with the AI/NAI distinction is to account for the special kind of incrementation that depends on communicative goals (stipulated by QUDs). Though the purposes of this work are scenic, it tries to point out new directions for the RRT, recognizing the merits of its appealing central idea: that utterances are interpreted in terms of an architecture of truth-conditions that depends on information harnessing and rationality. 


\section{References}

ABBOTT, B. "Presuppositions as non-assertions". Journal of Pragmatics, Vol. 32, Nr.10, pp.1419-1437, 2000.

. "Issues in the semantics and pragmatics of definite descriptions in English". In: GUNDEL, J. K., HEDBERG, N. (eds.). Reference: Interdisciplinary Perspectives. Oxford: Oxford University Press, 2008, pp. 61-72.

BEALER, G. "Quality and Concept". Oxford: Clarendon Press, 1982.

. "A Solution to Frege's Puzzle". Philosophical Perspectives, Vol. 7, Language and Logic, pp. 17-60, 1993.

BEAVER, D. "The kinematics of presupposition". In: DEKKER, P., STOCKHOF, M. (eds.) Proceedings of the Eighth Amsterdam Colloquium. Amsterdam: ILLC, University of Amsterdam, 1992. pp. 17-36.

CAPPELEN, H.; LEPORE, E. “The myth of unarticulated constituents". In: O'ROURKE, M., WASHINGTON, C. (eds.). Situating semantics: Essays on the philosophy of John Perry. Cambridge, MA: MIT Press, 2007. pp. 199-214.

CLARK, H. H., WILKES-GIBBS, D. "Referring as a collaborative process". Cognition, Vol. 22, Nr. 1, pp.1-39, 1986.

CLARK, H. H. "Arenas of language use". Chicago: University of Chicago Press, 1992. CRIMMINS, M. "Talk About Beliefs". Cambridge, MA: MIT Press, 1992.

FRIEND, S. "Believing in stories". In: CURRIE, GM KIERAN, M., MESKIN, A., ROBSON, J. (eds.) Aesthetics and the Sciences of Mind. Oxford: Oxford University Press, 2014. pp. 227-248.

GARCIA-CARPINTERO, M. "Token-Reflexivity and Indirect Discourse". In: HINTIKKA, A., NEVILlE, R., SOSA, E., OLSON, A. (eds.) The Proceedings of the Twentieth World Congress of Philosophy. Bowling Green, Ohio: Philosophy Documentation Center, 2000. pp. 37-56.

GRICE, H. P. "Presupposition and conversational implicature". In: COLE, P (ed.) Radical Pragmatics. New York: Academic Press, 1981. pp. 183-198.

HORN, L. "Toward a Fregean Pragmatics: Voraussetzung, Nebengedanke, Audeutung". In: KECSKES, I., HORN, L. (eds.) Explorations in Pragmatics: Linguistic, Cognitive and Intercultural Aspects. Berlin: Mouton de Gruyter, 2007. pp. 39-72.

KAPLAN, D. Demonstratives. In: ALMOG, J., PERRY, J., WETTSTEIN, H. (eds.) Themes from Kaplan. Oxford University Press, 1989. pp. 481-563.

KARTTUNEN, L. "Implicative verbs". Language, Vol. 47, Nr. 2, pp. 340-358, 1971 a. . "Some Observations on Factivity". Papers in Linguistics, Vol. 4, Nr. 1, pp. 55-69, $1971 \mathrm{~b}$.

. "Presuppositions of Compound Sentences". Linguistic Inquiry, Vol. 4, Nr. 2, pp. 167-193, 1973.

. "Presuppositions and Linguistic Context". Theoretical Linguistics, Vol. 1, Nr. 1-3, pp. 181-194, 1974.

KEMPSON, R. "Presupposition and the Delimitation of Semantics". Cambridge UK: Cambridge University Press, 1975. 
KORTA, K., PERRY, J. “Critical pragmatics: An inquiry into reference and communication”. Cambridge: Cambridge University Press, 2011.

KRIPKE, Saul A. "Naming and necessity". Cambridge MA: Harvard University Press, 1980.

LEWIS, D. "Scorekeeping in a language game”. Journal of Philosophical Logic, Vol. 8, Nr. 1, pp. 339-359, 1979.

MAIER, E. "Proper names and indexicals trigger rigid presuppositions". Journal of semantics, Vol. 26, Nr. 3, pp. 253-315, 2009.

MARTI, G. "The essence of genuine reference". Journal of Philosophical Logic, Vol. 24, Nr. 3, pp. 275-289, 1995.

MICHAELSON, R., REIMER, M. "Reference”. In: ZALTA, N. (ed.) The Stanford Encyclopedia of Philosophy (spring 2019 edition). Accessed on July, 2019.

O'ROURKE, M., WASHIGNTON, C. "Situating Semantics: Essays on the Philosophy of John Perry". Cambridge MA: MIT Press, 2007.

PERRY, J. "The problem of the essential indexical and other essays". Palo Alto: CSLI Publications, 2000.

" "Reference and reflexivity". Palo Alto: CSLI Publications, 2001.

RECANATI, F. “Unarticulated constituents”. Linguistics and Philosophy, Vol. 25, Nr. 3, pp. 299-345, 2002.

ROBERTS, C. "Information Structure in Discourse: Towards an Integrated Formal Theory of Pragmatics". In: YOON, J., KATHOL, A (eds.) OSU Working Papers in Linguistics No. 49: Papers in Semantics. The Ohio State University. Updated version of 1998 at: http://www.ling.ohiostate.edu/ croberts, 1996.

"Uniqueness in Definite noun phrases". Linguistics and Philosophy, Vol. 26, Nr. 3, pp. 287-350, 2003.

"Information structure: Afterword". Semantics and Pragmatics, Vol. 5, Nr.

7, pp.1-19, 2012.

. "Accommodation in a Language game". In: LOEWER, B., SCHAFFER, J. (eds.) A Companion to David Lewis. Chichester: Wiley Blackwell, 2015. pp. 345-366. ROBERTS, C; SIMONS, M.; BEAVER, D., TONHAUSER, J. "Presupposition, conventional implicature, and beyond: a unified account of projection". In: KLINEDIST, N., ROTHSCHILD, D. (eds.). Proceedings of the ESSLLI 2009 Workshop New Directions in the Theory of Presupposition, Bourdeaux, 2009. pp. 1-15.

SENNET, A. "Unarticulated constituents and propositional Structure". Mind and language, Vol. 26, Nr. 4, pp. 412-435, 2011.

SIMONS, M. "Presupposition and relevance". In: SZABÓ, Z. G. (ed.). Semantics vs. Pragmatics. Oxford: Oxford University Press, 2005. pp. 329-355.

SIMONS, M., TONHAUSER, J., ROBERTS, C., BEAVER, D. "What projects and why". In: LI, NAN, LUTZ, D. Semantics and linguistic theory (SALT) 20. Ithaca, NY: CLC Publications, 2010. pp. 309-327.

SOAMES, S. "Presupposition”. In: GABBAY, D. M., GUENTHENER, F. Handbook of philosophical logic. Dordrecht: Kluwer Academic, 1989. pp. 553-616. 
STALNAKER, R. "Presuppositions". Journal of Philosophical Logic, Vol. 2, Nr. 4, pp. 447-457, 1973.

. "Pragmatic Presuppositions". In: STALNAKER, R. (ed.). Context and Content. Oxford: Oxford University Press, 1974. pp. 47-62. 701-721, 2002.

. "Common Ground". Linguistics and Philosophy, Vol. 25, Nr. 5-6, pp.

. "Context". Oxford: Oxford University Press, 2014.

STRAWSON, P. F. “On referring”. Mind, Vol. 59, Nr. 235, pp. 320-344, 1950.

TAYLOR, K. "Meaning, reference and cognitive significance". Mind \& language, Vol. 10, Nr. 1-2, pp. 129-180, 1995.

. "Names as devices of Explicit co-reference". Erkenntnis, Vol. 80, Nr. 2, pp. 235-262, 2015.

VAN DER SANDT, R. "Presupposition projection as anaphora resolution". Journal of semantics, Vol. 9, Nr. 4, pp. 333-377, 1992.

VON FINTEL, K. "Would you believe it? The king of France is back! Presuppositions and truth-value intuitions". In: REIMER, M., BEZUIDENHOUT, A. Descriptions and Beyond. Oxford: Oxford University Press, 2004. pp. 269-296.

WALTON, K. "Mimesis as make-believe: On the foundations of the representational arts." Cambridge MA: Harvard University Press, 1990.

WETTSTEIN, H. "Has Semantics Rested on a Mistake?". Journal of Philosophy, Vol. 83, Nr. 4, pp. 185-209, 1986.

WILSON, D. "Presupposition and Non-truth-conditional Semantics". Cambridge: Academic Press, 1975.

XIANG, M., GROVE, J., GIANNAKIDOU, A. Dependency-dependent interference: NPI interference, agreement attraction, and global pragmatic inferences. Frontiers in psychology, 2013. Available at: https://doi.org/10.3389/fpsyg.2013.00708. 
